\title{
Spreading like wildfire
}

\author{
The 2017 wildfire season has seen unusually high fire levels in many parts of the world, with extensive \\ and severe fires occurring in Chile, the Mediterranean, Russia, the US, Canada and even Greenland. Is \\ this a sign of things to come?
}

During January and February, Chile experienced what their president Michelle Bachelet called "The greatest forest disaster in our history". The nation was not adequately equipped to tackle these fires, leading the government to enact a state of emergency and accept help from the US, France, Peru and Mexico. The fires burned more than 364,000 ha. A combination of long-term drought and high temperatures facilitated these extreme fires. The expansion of large, monoculture plantations of highly combustible trees such as eucalyptus and pine are also believed to be responsible for the extreme intensity of the blazes in Chile.

As the seasons progressed through the northern hemisphere, Southern Europe also experienced an unusually high fire season. The European Forest Fire Information System (EFFIS) (http://go.nature.com/2yrNlPd) shows the geographical pattern of fires and provides an indication of how unusual the 2017 season has been. This year's total burned area is estimated at about 622,000 ha compared with a 2008-2016 average of around 228,000 ha. Notable fires blazed in France, close to the city of Nice, and in Croatia around the historic city of Split. Portugal suffered particularly badly, with an estimated 141,000 ha affected and more than 60 people killed. At one point Mação, a town in central Portugal, was completely cut off by flames and smoke.

The US has also experienced an exceptional fire season with California, Colorado, Idaho, Montana, Nevada, Oregon, Utah, Washington and Wyoming all experiencing severe fires, with the burned area totalling an estimated 324,000 ha so far. Fires in Northern California were still blazing at the time of writing, with 23 people confirmed dead, many more still missing and more than 20,000 people asked to evacuate as a precautionary measure.

Perhaps most surprisingly, in August wildfires were spotted on the western coast of icy Greenland, northeast of the second-largest town, Sisimiut (pictured). These appear to be peat fires and while they are not unprecedented in Greenland they are considerably larger than have been seen previously, mirroring the wider pattern of fire severity in 2017. Dark soot particles deposited on ice and snow pose a potential risk of accelerating ice loss; this is an added concern if fires do become more prevalent on Greenland.

So what should we take away from these events? Fire is a natural and unavoidable feature of the environment in most of these locations and indeed wildfires perform important ecosystem functions. However, the 2017 fire season illustrates just how devastating they can be, posing risks to human life and health as well as property, even in rich, wellresourced nations. Climate is just one of the many factors influencing wildfire risk, but the right climatic conditions enable fires to take hold and spread quickly. In many cases it's not so much the number of fires that increases in a high fire year but the severity and size of the burn area resulting from fires once started. However, lightning can influence ignitions too (Veraverbeke, S. et al. Nat. Clim. Change 7, 529-534; 2017). Many other factors including land use, fire prevention measures and increasing population densities combine to increase the direct risks that fires can pose to human life and property (for example, Knorr, W., Arneth, A. and Jiang, L. Nat. Clim. Change 6, 781-785; 2016). Nevertheless, while high fire years such as 2017 are not unprecedented, it seems likely that the hot dry conditions - some of which are regionally record breaking - that facilitated these fires will become more common with climate change. Given that these high fire years are already testing our ability to manage fire in the landscape while avoiding significant risk to life and livelihoods, an expected increase in their frequency is a daunting prospect.

In addition to posing direct risks to people living in and around fire-stricken areas, fire is an important disturbance process which influences ecosystem stability and in particular can influence their carbon balance. Fire events can

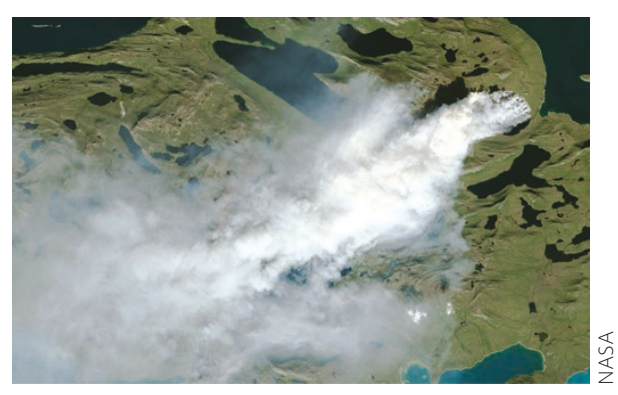

release significant amounts of $\mathrm{CO}_{2}$ into the atmosphere and alter the productivity, and therefore carbon absorption capacity, of those ecosystems. Understanding the dynamics of fire risk is therefore important for understanding land carbon sinks and sources and their potential to reinforce or attenuate climatic changes. In particular, the vulnerability of some monoculture forest plantations, as found in Chile, raises questions about the suitability of afforestation programmes intended to take up carbon if they follow this monoculture approach. See this Perspective for a discussion of the benefits of more diverse plantings (Hulvey, K. B. et al. Nat. Clim. Change 3, 869-874; 2013).

What might now be considered high wildfire years like 2017 are likely to become more common in the future and this will inevitably stretch the existing institutional and infrastructural resources in place to manage them - resources that have already been shown to be inadequate this year in many places. There will be many lessons from this fire season that could be used to guide adaptation planning. Climate change is only one of the factors driving increased risk from wildfire, but it may already be facilitating fire in regions where it was previously rare and small in scale, such as Greenland. Earth-monitoring efforts (for example, http://go.nature.com/2yrcwB2 and http://go.nature.com/2xI90P8) as well as on the ground research seem to be ever more valuable resources as we try to manage the direct and indirect risks that changing wildfires pose to people and the environment. 